\title{
Midbrain Atrophy Related to Parkinsonism in a Non- Coding Repeat Expansion Disorder: Five Cases of Spinocerebellar Ataxia Type 31 With Nigrostriatal Dopaminergic Dysfunction
}

\section{Ryohei Norioka;}

Tokyo Metropolitan Neurology Hospital: Tokyo Toritsu Shinkei Byoin

Keizo Sugaya ( $\square$ keizo_sugaya@member.metro.tokyo.jp)

Tokyo Metropolitan Neurological Hospital https://orcid.org/0000-0002-6334-1289

\section{Aki Murayama}

Tokyo Metropolitan Neurological Hospital: Tokyo Toritsu Shinkei Byoin

\section{Tomoya Kawazoe}

Tokyo Metropolitan Neurological Hospital: Tokyo Toritsu Shinkei Byoin

\section{Shinsuke Tobisawa}

Tokyo Metropolitan Neurological Hospital: Tokyo Toritsu Shinkei Byoin

\section{Akihiro Kawata}

Tokyo Metropolitan Neurological Hospital: Tokyo Toritsu Shinkei Byoin

\section{Kazushi Takahashi}

Tokyo Metropolitan Neurological Hospital: Tokyo Toritsu Shinkei Byoin

\section{Research}

Keywords: Spinocerebellar ataxia type 31, Nigrostriatal dopaminergic dysfunction, Midbrain atrophy, Parkinsonism, Magnetic resonance imaging planimetry, non-coding repeat expansion disorder

Posted Date: January 7th, 2021

DOl: https://doi.org/10.21203/rs.3.rs-139248/v1

License: (c) (1) This work is licensed under a Creative Commons Attribution 4.0 International License. Read Full License 


\section{Abstract}

\section{Background}

Spinocerebellar ataxia type 31 (SCA31) is caused by non-coding pentanucleotide repeat expansions in the BEAN1 gene. Clinically, SCA31 is characterized by late-adult onset, pure cerebellar ataxia. To explore the association between parkinsonism and SCA31, five patients with SCA31 with concomitant nigrostriatal dopaminergic dysfunction (NSDD) development, including three cases of L-DOPA responsive parkinsonism, were characterized.

Methods

To assess regional brain atrophy, cross-sectional and longitudinal imaging analyses were retrospectively performed using Magnetic resonance imaging (MRI) planimetry. The midbrain-to-pons (M/P) area ratio and cerebellar area were measured on midsagittal T1-weighted MRI in five patients with NSDD $(\operatorname{NSDD}(+)), 14$ patients with SCA31 without NSDD (NSDD(-)), 32 patients with Parkinson's disease (PD), and 15 patients with progressive supranuclear palsy. Longitudinal changes in the M/P area ratio were assessed by serial MRI of $\operatorname{NSDD}(+)(n=5)$ and $\operatorname{NSDD}(-)(n=9)$.

Results

The clinical characteristics relevant to parkinsonism in $\operatorname{NSDD}(+)$ were indistinguishable from those of PD except for the prominence of bradykinesia/akinesia (5/5) and the absence of dysautonomia (5/5). However, a clear reduction in the midbrain area and the M/P area ratio was observed in $\operatorname{NSDD}(+)(p$ $<0.05)$ while there was no significant difference in disease duration or in the pons area among NSDD $(+)$, $\operatorname{NSDD}(-)$, and PD. A faster rate of decline in the midbrain area and the M/P area ratio was evident in $\operatorname{NSDD}(+)(p<0.05)$.

Conclusion

The unique features of midbrain atrophy related to NSDD in our patients suggest that SCA31 belongs to the group of non-coding repeat expansion disorders causing parkinsonism.

\section{Introduction}

Spinocerebellar ataxia type 31 (SCA31) is an inherited neurodegenerative disorder characterized by slowly progressive, late-adult onset, pure cerebellar ataxia [1,2]. SCA31 is caused by an insertion mutation of variable-length (2.5-3.8 kb) containing (TGGAA)n within the intron of the brain-expressed associated with NEDD4 1 (BEAN1) gene [3]. A few cases of SCA31 presenting with extracerebellar signs, including parkinsonism, postural tremor, dystonia, and spastic paraparesis, have been reported [4-6]. In Japan, genetic testing for SCA31 is usually performed in patients with pure cerebellar ataxia but yields a bias against extracerebellar manifestations of SCA31, and only a few patients with SCA31 have 
undergone neuropathological assessment. Therefore, the extracerebellar manifestations in patients with SCA31 are still largely unknown.

The present study analyzed five cases of SCA31 with nigrostriatal dopaminergic dysfunction (NSDD), which is defined as the presence of at least two of the three cardinal motor symptoms of Parkinson's disease (PD), including resting tremor, rigidity, and bradykinesia/akinesia or one of the three cardinal motor symptoms plus an abnormal ${ }^{123}$-ioflupane dopamine transporter (DAT) scintigraphy finding. We aimed to describe the clinical characteristics of these cases and to explore the association between NSDD and SCA31. Cross-sectional and longitudinal imaging analyses were retrospectively conducted to assess regional brain atrophy in the midbrain and pons in the patients with NSDD and the control subjects.

\section{Patients And Methods}

\section{Patients}

Between April 2010 and December 2019, 20 patients with cerebellar ataxia caused by a genetic mutation responsible for SCA31 were referred to our hospital. Of these, NSDD developed in five patients. In total, 19 patients with SCA31 underwent cross-sectional imaging analysis using Magnetic resonance imaging (MRI) planimetry and were divided into the SCA31 with $\operatorname{NSDD}$ group $(\operatorname{NSDD}(+), n=5)$ and the SCA31 without NSDD group (NSDD(-), $n=14)$. One patient was excluded due to having infarcts affecting the midline sagittal MRI assessments. Serial brain MRI examinations and longitudinal imaging analysis were performed in all five patients with $\operatorname{NSDD}(+)$ and in nine of the 14 patients with NSDD(-).

Between January 2019 and July 2020, 39 patients with PD who fulfilled the movement disorder society (MDS) clinical diagnostic criteria for 'clinically estabilished PD' were referred to our hospital [7]. To exclude juvenile PD, three patients who were younger than 50 years at onset were excluded. PD is susceptible to clinical misdiagnosis, especially in its earlier stages. For this reason, four patients who had a disease duration of less than three years from onset were also excluded. In total, 32 patients with PD underwent cross-sectional imaging analysis.

Between January 2018 and July 2020, 15 patients with PSP who fulfilled the MDS clinical diagnostic criteria for 'probable PSP' were referred to our hospital [8]. All these patients underwent cross-sectional imaging analysis.

\section{Clinical data}

Clinical data were collected from medical records. After obtaining informed consent, imaging studies of DAT scintigraphy and 3-Tesla (3-T) neuromelanin MRI were performed in four patients with NSDD. DAT scintigraphy was not performed in one patient due to the lack of consent. DAT scintigraphy and 3-T neuromelanin MRI were not performed in another patient with NSDD due to the development of lung 
cancer. The 3-T neuromelanin MRI was performed in accordance with the previously described method [9].

\section{Gene analysis}

After written informed consent was obtained, genomic DNA was extracted from peripheral-blood leukocytes and tested for SCA1, 2, 3, 6, 7, 8, 12, 17, and dentatorubral-pallidoluysian atrophy (DRPLA) using the previously described method [10]. SCA31 was diagnosed in patients showing both a singlenucleotide $\mathrm{C} \rightarrow$ T substitution in the $5^{\prime} \mathrm{UTR}$ of the puratrophin-1 gene and a pentanucleotide insertion in the introns of the TK2 and BEAN1 genes [1-3]. To visualize the $\mathrm{C} \rightarrow$ T substitution in the $5^{\prime} \mathrm{UTR}$ of the puratrophin-1 gene, the genomic DNA was amplified by PCR method (Forward primer: 5'CAGCGCGGTTCACACTGAGA-3', Reverse primer: 5'-GGCCCTTTCTGACAGGACTGA-3'), and the PCR product was digested by EcoN1. The patients with SCA31 had the $\mathrm{C} \rightarrow \mathrm{T}$ substitution in the mutant allele, which disrupted one EcoNI site and produced fragments of 268 and 92 bp [11]. Analysis of the insertion mutation was performed using the following method [12]. Briefly, genomic DNA $100 \mathrm{ng}$ was mixed with $10 \mu \mathrm{M}$ primer $0.75 \mu \mathrm{l}$ (Forward primer: 5'-ACTCCAACTGGGATGCAGTTTCTCAAT-3', Reverse primer: 5'CTTTAGGGACCTGATTTCCTTCCTCCA-3') in a total volume of $25 \mu \mathrm{l}$ containing 2 X-PCR buffer $12.5 \mu \mathrm{l}$ for KODFX (TOYOBO), dNTP $400 \mu \mathrm{M}, \mathrm{H}_{2} \mathrm{O} 5 \mu \mathrm{l}$, and KODFX $0.5 \mu \mathrm{l}$ (TOYOBO). The samples were denatured at $95^{\circ} \mathrm{C}$ for $5 \mathrm{~min}$, followed by 35 cycles at $95^{\circ} \mathrm{C}$ for $20 \mathrm{sec}$ and at $68^{\circ} \mathrm{C}$ for $8 \mathrm{~min}$. The PCR products were run on $1.5 \%$ agarose gel.

\section{MRI planimetry}

All the patients underwent brain MRI with a 3-T MRI scanner (750 GE). MRI-based planimetry on midsagittal T1-weighted MRI was performed to measure the area of the midbrain, pons, and cerebellum and to calculate the midbrain-to-pons $(M / P)$ and the cerebellum-to-pons $(C / P)$ area ratios. The pontomesencephalic junction was defined by a line between the superior pontine notch and the inferior border of the quadrigeminal plate [13]. The pontomedullary junction was defined by a line parallel to the first line at the level of the inferior pontine notch. Image analysis was done by blinded investigators using ImageJ software (version 1.52). First, a region of interest (ROI) was located in the area of the pontine tegmentum to derive the mean individual background signal and SD. Then, the ROls were manually outlined as described above. To delineate the boundary of the ROls, the area in each ROI was measured by a signal intensity value higher than the mean individual background signal minus 3SD (midbrain, pons) or the mean background signal minus 8SD (cerebellum). Two neurologists acting as independent raters blinded to the diagnosis analyzed the images.

\section{Cross-sectional imaging analysis}

The area of the midbrain, pons, and cerebellum was measured in patients with SCA31, and the area of the midbrain and pons was measured in patients with PD and PSP. The latest MRI scan was used for imaging analysis in each patient who had repetitive MRI examinations. 


\section{Longitudinal imaging analysis}

Serial MRI scans were done for all five patients with $\operatorname{NSDD}(+)$ and nine patients with NSDD(-). Two MRI scans were removed for further study due to severe motion artifacts. A total of $40 \mathrm{MRI}$ scans ( 15 for the $\operatorname{NSDD}(+)$ group and 25 for the NSDD(-) group) were used to measure the midbrain and pons area to calculate the M/P area ratio.

\section{Statistical analysis}

Continuous variables were checked for normality and homogeneity of variance with Shapiro-Wilk's and Levene's tests. Normally distributed data were analyzed using Student's t test or Welch test. The MannWhitney test was used when the variable was either ordinal or continuous, but not normally distributed. The difference between the two groups was judged to be statistically significant at if the $P$ value was 0.05 or less. Linear regression analysis was performed to determine the effect of disease duration on regional brain atrophy. Normality and homoscedasticity of the residuals were checked in the linear regression analyses. Statistical analyses were performed using IBM SPSS Statistics 20.

\section{Results}

\section{Clinical characteristics of patients with SCA31 complicated with NSDD}

Of the 20 genetically confirmed cases of SCA31, NSDD developed in five patients, including four presenting with rigidity and bradykinesia/akinesia and one presenting with bradykinesia/akinesia with an abnormal DAT scintigraphy finding. The clinical characteristics of cerebellar ataxia in SCA31, including slowly progressive, late-adult onset ataxia, eye movement abnormalities with saccade and horizontal gaze-evoked nystagmus, and prominent atrophy of the upper cerebellum, were observed equally in patients with and without NSDD. The clinical and imaging features of parkinsonism and the related symptoms in the five patients with NSDD (Table 1) were as follows: L-DOPA responsive parkinsonism $(3 / 3)$, prominence of bradykinesia/akinesia (5/5), dysautonomia (0/5), vertical gaze limitation (1/5), pons atrophy (0/5), putamen atrophy $(0 / 5)$, and abnormal DAT scintigraphy $(3 / 3)$, and 3-T neuromelanin MRI (4/4) findings. NSDD developed in all the patients after the onset of cerebellar ataxia.

\section{Cross-sectional imaging analysis in patients with SCA31 complicated with NSDD}

Table 2 summarizes the demographic features of 19 patients with SCA31 with or without NSDD, 32 patients with PD and 15 patients with PSP and the results of the cross-sectional imaging analysis. First, to estimate the influence of disease duration on the midbrain area, pons, and cerebellum, linear regression analysis was used to assess the relationship between disease duration at MRI acquisition versus $\mathrm{M} / \mathrm{P}$ area ratio and the relationship between disease duration at MRI acquisition and the $\mathrm{C} / \mathrm{P}$ area ratio in all 19 patients with SCA31 (Supplementary Fig. 1). As expected, there was a significant effect of disease duration on the $\mathrm{C} / \mathrm{P}$ area ratio (coefficient of determination, $R^{2}=0.305, p=0.014$ ). Whereas, there was no significant effect of disease duration on the M/P area ratio $\left(R^{2}=0.157, p=0.093\right)$, although there 
was a weak, linear relationship between the variables. The patients were then divided into two groups according to the presence or absence of NSDD (NSDD(+): SCA31 with NSDD, $n=5, \operatorname{NSDD}(-)$ : SCA31 without NSDD, $n=14)$. All five patients with NSDD were male; thus, NSDD(-) was subdivided into male patients without NSDD $(n=9, \operatorname{NSDD}(-) m)$. An apparent reduction in the midbrain area and the M/P area ratio was observed in $\mathrm{NSDD}(+)(p<0.05)$ while there was no statically significant difference in disease duration at MRI acquisition or in the $\mathrm{C} / \mathrm{P}$ area ratio among the three groups (Table 2). Furthermore, the NSDD (+) findings were compared to the findings in the 32 patients with PD and 15 patients with PSP. For statistical comparison, these patients were further divided into male patients with PD (PDm) and male patients with PSP (PSPm). There was a clear difference in the midbrain area and the M/P area ratio between the $\operatorname{NSDD}(+)$ and PD groups and between the NSDD $(+)$ and PDm groups $(p<0.05)$ (Table 2$)$. In line with previous studies, the PSP group showed a severe reduction in the midbrain and pons area than that of PD group [13-16]. There was also a clear difference in the midbrain and pons area between the $\operatorname{NSDD}(+)$ and PSP groups and between the NSDD $(+)$ and PSPm groups $(p<0.05)($ Table 2$)$. These results suggest mild but significant midbrain atrophy in patients with NSDD. Figure 1 shows midbrain tegmentum atrophy in a representative case of NSDD and the result of the comparison of the M/P area ratio in these groups. Image analysis by an independent investigator confirmed these results.

\section{Longitudinal imaging analysis in patients with SCA31 complicated with NSDD}

A previous, longitudinal study reported the regional rates of atrophy of $0.3 \% / y e a r$ in the midbrain and $0.2 \% /$ year in the pons in healthy adult subjects [17]. From these data, the rate of reduction in the M/P area ratio was estimated to be $0.001 /$ year $(\mathrm{M} / \mathrm{P}$ area ratio at time $0=1)$. Thus, the M/P area ratio may be useful for minimizing the effect of age on midbrain atrophy. Longitudinal changes in the M/P area ratio were calculated using serial brain MRI obtained from patients with $\operatorname{NSDD}(+)(n=5)$ and $\operatorname{NSDD}(-)(n=9)$. The NSDD (-) group was further divided into male patients without NSDD ( $n=6, \operatorname{NSDD}(-) m)$. Table 3 summarizes the demographic features, average number of MRI examinations, and the mean interval between the MRI and the results of longitudinal imaging analyses in the three groups. To normalize the individual difference, the reduction ratio of the M/P area ratio was calculated as follows: the M/P area ratio derived from the first MRI examination was defined as 1 , and the M/P area ratio derived from the second or later MRI was divided by the M/P area ratio derived from the first MRI in each patient. Liner regression of the reduction ratio of the M/P area ratio over time in the NSDD $(+)$ group showed a significant effect of disease duration on the reduction ratio of the M/P area ratio $\left(R^{2}=0.267, p=0.0488\right)$ (Fig. 2A). Whereas, liner regression of the reduction ratio of the M/P area ratio over time in the NSDD(-) and $\operatorname{NSDD}(-) m$ groups showed no significant effect of disease duration on the reduction ratio of the M/P area ratio $\left(R^{2}=0.044, p=0.312\right.$ and $R^{2}=0.031, p=0.471$, respectively) (Fig. 2.B.C). The difference in the linear regression slopes (Fig. 2) between the $\operatorname{NSDD}(+)$ and $\operatorname{NSDD}(-)$ groups and between the $\operatorname{NSDD}(+)$ and NSDD(-)m groups was also tested (Supplementary File 1) and the result confirmed a faster rate of decline in the M/P area ratio in the $\operatorname{NSDD}(+)$ group. There was a clear difference in the reduction ratio of the midbrain area and the M/P area ratio in the $\operatorname{NSDD}(+)$ group $(p<0.05)$ while no significant difference in the reduction ratio of the pons area or in the mean interval between the MRI was observed among the 
three groups (Table 3). Thus, a faster rate of decline in the midbrain area as well as the M/P area ratio was evident in the $\operatorname{NSDD}(+)$ group. These results suggest a significant progression of midbrain atrophy in patient with NSDD.

\section{Discussion}

The M/P area ratio as measured on the midline sagittal images is reportedly a simple and reliable metric for distinguishing PSP from PD and multiple system atrophy (MSA) [13-16]. A statistically significant decrease in the midbrain area and the M/P area ratio was found in patients with SCA31 complicated with NSDD (Table 2, Fig. 1). Compared to the PSP findings, the midbrain atrophy was mild and no pontine atrophy was evident. Further observation of the progression of the midbrain atrophy in these patients suggested that a relationship exists between midbrain atrophy and NSDD pathogenicity. Midbrain atrophy was also reported in patients with vascular parkinsonism [18]. In the present study, all five patients with NSDD had no medical history of stroke or diffuse subcortical white matter ischemia. The clinical characteristics relevant to parkinsonism in the patients with NSDD, together with the topographical pattern of atrophy, were inconsistent with those of PD, PSP or MSA. Furthermore, genetic testing excluded the other types of SCA, including SCA1, 2, 3, 6, 7, 8, 12, 17, and DRPLA. Thus, the findings of the present study raised the possibility of an association between NSDD and the pathomechanisms underlying SCA31 despite the fact that to date, only a single-case report describing an association between SCA31 and parkinsonism has been published [4]. Importantly, compared to a typical patient with PD, the patients in the present study showed mild rigidity due to the hypotonia of cerebellar injury before parkinsonism onset, prominence of bradykinesia/akinesia, and reduced spontaneous activity, including speech and voluntary movements. These features may lead to an underestimation of parkinsonism in patients with SCA31.

SCA31 is a form of non-coding repeat expansion disorders that can be pathologically characterized by RNA foci formation and repeat-associated non-AUG translation [19-20] The underlying mechanism of non-coding repeat sequence mediated neurotoxicity is still uncertain. However, a previous study reported that above a pathological threshold repeat number, base pairing interactions drive liquid phase separation of RNA into membraneless gels as RNA foci [21]. The gelation of intracellular compartments may result in neurotoxicity by sequestering RNA binding proteins (RBPs) and inhibiting their normal function [21, 22]. A recent study found that ALS-linked RBP, TDP-43, and FUS, bound to and induced structural alteration of SCA31-associated UGGAA repeat expansion, with a formation of RNA foci [23]. Interestingly, a mutation in the TARDBP gene encoding TDP-43 was identified as a cause of familial PD, presumably due to loss of TDP-43 function [24]. Recently, the authors of the present study experienced a case of essential tremor with no other neurological findings, including cerebellar ataxia, in which the results of a genetic test revealed an insertion mutation responsible for the SCA31 phenotype. Another study found that a loss-of-function mutation in the FUS gene caused essential tremor [25]. Thus, loss of function of RBPs binding specifically to UGGAA repeats within RNA foci can potentially explain the extracerebellar manifestations of SCA31. 
The present study has several limitations. Because the study was retrospective and enrolled a small number of subjects, estimating the actual incidence of NSDD in SCA31 and the gender difference in relation to the risk of developing NSDD was difficult. All five patients with NSDD were male, and SCA31 was characterized by late-adult onset. Therefore, gender and age effects on regional brain atrophy were carefully considered. To minimize these effects, the male patients with NSDD(-), PD or PSP were compared statistically and longitudinal changes in the M/P area ratio were assessed. Indeed, the M/P area ratio minimized the effect of age on regional brain atrophy (Fig. 2.B.C). A growing number of diseases caused by non-coding repeat expansions are often associate with parkinsonism, including fragile X-associated tremor/ataxia syndrome (FXTAS) and neuronal intranuclear inclusion disease [26, 27]. Midbrain atrophy-related parkinsonism was reported in patients with FXTAS although its association with this disease remains elusive [28-30]. Further studies are required to clarify the association between NSDD and SCA31. This in turn will be helpful in understanding the pathomechanisms underlying SCA31 and parkinsonism associated with non-coding repeat expansion disorders.

\section{Conclusion}

The present study revealed unique features of NSDD and shed light on its relationship to midbrain atrophy in patients with SCA 31, suggesting that SCA31 belongs to the group of non-coding repeat expansion disorders causing parkinsonism

\section{Declarations}

\section{Acknowledgments}

The authors sincerely thank the members of the Department of Neuroradiology, Tokyo Metropolitan Neurological Hospital for assistance with imaging analysis.

\section{Ethics declarations}

\section{Funding}

This research did not receive any specific grant from funding agencies in the public, commercial, or notfor-profit sectors

\section{Conflicts of interest/Competing interests}

The authors declare no conflicts of interest associated with this manuscript

\section{Ethics approval}

The local Ethical Committee of Tokyo Metropolitan Neurological Hospital supervised and approved all procedures (TS-R02-016, TS-R02-033), including utilization of datasets of the control subjects (PD and PSP), in accordance with the Declaration of Helsinki (amended version 2013). All patients with SCA31 
provided written informed consent for the genetic analysis, the use of their clinical data for research purposes, and for publication. Under Japan law, no additional ethical approval is required for retrospective database studies.

\section{Availability of data and material}

Data is available on the reasonable request to the corresponding author.

\section{Code availability}

Not applicable.

\section{Author contributions}

RN and KS contributed to the study concept and design; acquisition, analysis and interpretation of data; imaging analysis; drafting the manuscript; critical revision of the manuscript for important intellectual content. AM undertook imaging analysis; interpretation of data and critical revision of the manuscript for important intellectual content. TK and AK undertook acquisition, analysis and interpretation of data; critical revision of the manuscript for important intellectual content. ST and KT interpretation of data; critical revision of the manuscript for important intellectual content. All authors approved the final version of the manuscript for publication.

\section{References}

[1] Ohata T, Yoshida K, Sakai H, Hamanoue H, Mizuguchi T, Shimizu Y, Okano T, Takada F, Ishikawa K, Mizusawa H, Yoshiura KI, Fukushima Y, Ikeda SI, Matsumoto N (2006) A-16C>T substitution in the 5' UTR of the puratrophin-1 gene is prevalent in autosomal dominant cerebellar ataxia in Nagano. J Hum Genet $51: 461-466$

[2] Owada K, Ishikawa K, Toru S, Ishida G, Gomyoda M, Tao O, Noguchi Y, Kitamura K, Kondo I, Noguchi E, Arinami T, Mizusawa $\mathrm{H}$ (2005) A clinical, genetic, and neuropathologic study in a family with $16 q$-linked

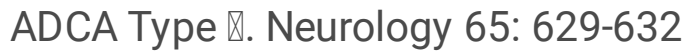

[3] Sato N, Amino T, Kobayashi K, Asakawa S, Ishiguro T, Tsunemi T, Takahashi M, Matsuura T, Flanigan KM, Iwasaki S, Ishino F, Saito Y, Murayama S, Yoshida M, Hashizume Y, Takahashi Y, Tsuji S, Shimizu N, Toda T, Ishikawa K, Mizusawa H (2009) Spinocerebellar ataxia type 31 is associated with "inserted" penta-nucleotide repeats containing (TGGAA)n. Am J Hum Genet 85:544-557

[4] Shimizu K, Hanajima R, Satou S, Shimizu T, Watanabe K, Kaneko A, lizuka T, Nishiyama K (2017) Holmes's tremor caused by coexisting Parkinson's disease in a case of spinocerebellar ataxia type 31 . Neurol Clin Neurosci 5:71-72

[5] Saito R, Kikuno S, Maeda M, Uesaka Y, Ida M (2014) A case of 77-year-old male with spinocerebellar ataxia type 31 with left dominant dystonia. Rinsho Shinkeigaku 54:643-647 
[6] Hasegawa A, Koike R, Koh K, Kawakami A, Hara N, Takiyama Y, Ikeuchi T (2017) Co-existence of spastic paraplegia-30 with novel KIF1A mutation and spinocerebellar ataxia 31 with intronic expansion of BEAN and TK2 in a family. J Neurol Sci 372:128-130

[7] Postuma RB, Berg D, Stern M, Poewe W, Olanow CW, Oertel W, Obeso J, Marek K, Litvan I, Lang AE, Halliday G, Goetz CG, Gasser T, Dubois B, Chan P, Bloem BR, Adler CH, DeuschI G (2015) MDS clinical diagnostic criteria for Parkinson's disease Mov Disord 30:1591-1601

[8] Höglinger GU, Respondek G, Stamelou M, Kurz C, Josephs KA, Lang AE, Mollenhauer B, Müller U, Nilsson C, Whitwell JL, Arzberger T, Englund E, Gelpi E, Giese A, Irwin DJ, Meissner WG, Pantelyat A, Rajput A, van Swieten JC, Troakes C, Antonini A, Bhatia KP, Bordelon Y, Compta Y, Corvol JC, Colosimo C, Dickson DW, Dodel R, Ferguson L, Grossman M, Kassubek J, Krismer F, Levin J, Lorenzl S, Morris HR, Nestor P, Oertel WH, Poewe W, Rabinovici G, Rowe JB, Schellenberg GD, Seppi K, van Eimeren T, Wenning GK, Boxer AL, Golbe LI, Litvan I; Movement Disorder Society-endorsed PSP Study Group (2017) Clinical diagnosis of progressive supranuclear palsy: The movement disorder society criteria. Mov Disord 32: 853-864

[9] Mukai M, Sugaya K, Yabe I, Goto Y, Yokochi F, Miyamoto K, Cai H, Sasaki H, Matsubara S (2013) Neuromelanin MRI in a family with mitochondrial parkinsonism harboring a Y955C mutation in POLG1. Park Relat Disord 19:821-824

[10] Aoki K, Kawata A, Suda M, Hirai S (2001) Clinical features of autosomal dominant spinocerebellar ataxias genetically unclassified into any known triplet-repeat diseases. Rinsho Shinkeigaku 41:18-23

[11] Ishikawa K, Toru S, Tsunemi T, Li M, Kobayashi K, Yokota T, Amino T, Owada K, Fujigasaki H, Sakamoto M, Tomimitsu H, Takashima M, Kumagai J, Noguchi Y, Kawashima Y, Ohkoshi N, Ishida G, Gomyoda M, Yoshida M, Hashizume Y, Saito Y, Murayama S, Yamanouchi H, Mizutani T, Kondo I, Toda T, Mizusawa $\mathrm{H}$ (2005) An autosomal dominant cerebellar ataxia linked to chromosome 16q22.1 is associated with a single-nucleotide substitution in the 5'untranslated region of the gene encoding a protein with spectrin repeat and Rho guanine-nucleotide exchange-factor domains. Am J Hum Genet 77:280-296

[12] Sakai H, Yoshida K, Shimizu Y, Morita H, lkeda S, Matsumoto N (2010) Analysis of an insertion mutation in a cohort of 94 patients with spinocerebellar ataxia type 31 from Nagano, Japan.

Neurogenetics 11:409-415

[13] Oba H, Yagishita A, Terada H, Barkovich AJ, Kutomi K, Yamauchi T, Furui S, Shimizu T, Uchigata M, Matsumura K, Sonoo M, Sakai M, Takada K, Harasawa A, Takeshita K, Kohtake H, Tanaka H, Suzuki S (2005) New and reliable MRI diagnosis for progressive supranuclear palsy. Neurology 64:2050-2055

[14] Quattrone A, Nicoletti G, Messina D, Fera F, Condino F, Pugliese P, Lanza P, Barone P, Morgante L, Zappia M, Aguglia U, Gallo O (2008) MR imaging index for differentiation of progressive supranuclear palsy from Parkinson disease and the Parkinson variant of multiple system atrophy. Radiology 246:214221 
[15] Hotter A, Esterhammer R, Schocke MF, Seppi K (2009) Potential of advanced MR imaging techniques in the differential diagnosis of parkinsonism. Mov Disord 24(suppl 2):S711-720

[16] Massey LA, Micallef C, Paviour DC, O'Sullivan SS, Ling H, Williams DR, Kallis C, Holton JL, Revesz T, Burn DJ, Yousry T, Lees AJ, Fox NC, Jäger HR (2012) Conventional magnetic resonance imaging in confirmed progressive supranuclear palsy and multiple system atrophy. Mov Disord 27:1754-1762

[17] Paviour DC, Price SL, Jahanshahi M, Lees AJ, Fox NC (2006) Longitudinal MRI in progressive supranuclear palsy and multiple system atrophy: rates and regions of atrophy. Brain 129:1040-1049

[18] Choi SM, Kim BC, Nam TS, Kim JT, Lee SH, Park MS, Kim MK, de Leon MJ, Cho KH (2011) Midbrain atrophy in vascular Parkinsonism. Eur Neurol 65:296-301

[19] Wojciechowska M, Krzyzosiak WJ (2011) Cellular toxicity of expanded RNA repeats: focus on RNA foci. Hum Mol Genet 20:3811-3821

[20] Todd PK, Oh SY, Krans A, He F, Sellier C, Frazer M, Renoux AJ, Chen KC, Scaglione KM, Basrur V, Elenitoba-Johnson K, Vonsattel JP, Louis ED, Sutton MA, Taylor JP, Mills RE, Charlet-Berguerand N, Paulson H (2013) CGG repeat-associated translation mediates neurodegeneration in Fragile $X$ tremor ataxia syndrome. Neuron 78:440-455

[21] Jain A, Vale RD (2017) RNA phase transitions in repeat expansion disorders. Nature 546:243-247

[22] Saha S, Hyman AA (2017) RNA gets in phase. J Cell Biol 216:2235-2237

[23] Ishiguro T, Sato N, Ueyama M, Fujikake N, Sellier C, Kanegami A, Tokuda E, Zamiri B, Gall-Duncan T, Mirceta M, Furukawa Y, Yokota T, Wada K, Taylor JP, Pearson CE, Charlet-Berguerand N, Mizusawa H, Nagai Y, Ishikawa K (2017) Regulatory role of RNA chaperone TDP-43 for RNA misfolding and repeatassociated translation in SCA31. Neuron 94:108-124

[24] Rayaprolu S, Fujioka S, Traynor S, Soto-Ortolaza Al, Petrucelli L, Dickson DW, Rademakers R, Boylan KB, Graff-Radford NR, Uitti RJ, Wszolek ZK, Ross OA (2013) TARDBP mutations in Parkinson's disease. Park Relat Disord 19:312-315

[25] Merner ND, Girard SL, Catoire H, Bourassa CV, Belzil VV, Rivière JB, Hince P, Levert A, Dionne-Laporte A, Spiegelman D, Noreau A, Diab S, Szuto A, Fournier H, Raelson J, Belouchi M, Panisset M, Cossette P, Dupré N, Bernard G, Chouinard S, Dion PA, Rouleau GA (2012) Exome sequencing identifies FUS mutations as a cause of essential tremor. Am J Hum Genet 91:313-319

[26] Ma D, Tan YJ, Ng ASL, Ong HL, Sim W, Lim WK, Teo JX, Ng EYL, Lim EC, Lim EW, Chan LL, Tan LCS, Yi Z, Tan EK (2020) Association of NOTCH2NLC repeat expansions with Parkinson disease. JAMA Neurol. https://doi.org/10.1001/jamaneurol.2020.3023 
[27] Shi CH, Fan Y, Yang J, Yuan YP, Shen S, Liu F, Mao CY, Liu H, Zhang S, Hu ZW, Fan LY, Li MJ, Fan SH, Liu XJ, Xu YM, NOTCH2NLC (2020) Intermediate-Length Repeat Expansions Are Associated with Parkinson Disease. Ann Neurol. https://doi.org/10.1002/ana.25925

[28] De Pablo-Fernandez E, Doherty KM, Holton JL, Revesz T, Djamshidian A, Limousin P, Bhatia KP, Warner TT, Lees AJ, Ling H (2015) Concomitant fragile X-associated tremor ataxia syndrome and Parkinson's disease: a clinicopathological report of two cases. J Neurol Neurosurg Psychiatry 86:934-936

[29] Paucar M, Beniaminov S, Paslawski W, Svenningsson P (2016) PSP-CBS with dopamine deficiency in a female with a FMR1 premutation. Cerebellum 15:636-640

[30] Salomão RPA, Vale TC, Marussi VHR, Barsottini OGP, Pedroso JL (2019) Late-onset hummingbird sign in a woman with fragile $X$ premutation. $J$ Neurol Sci 403:75-77.

\section{Tables}

Table 1. Clinical characteristics of five patients with SCA31 complicated with NSDD 


\begin{tabular}{|c|c|c|c|c|c|}
\hline Patient & 1 & 2 & 3 & 4 & 5 \\
\hline Sex & M & M & M & $M$ & $M$ \\
\hline Age at onset & 52 & 57 & 64 & 73 & 72 \\
\hline Age at NSDD onset & 59 & 60 & 84 & 74 & 83 \\
\hline Age at MRI & 63 & 61 & 85 & 77 & 83 \\
\hline Family history & + & + & + & - & + \\
\hline L-DOPA response & + & + & + & NE & $\mathrm{NE}$ \\
\hline \multicolumn{6}{|l|}{ Symptoms } \\
\hline Cerebellar ataxia & + & + & + & + & + \\
\hline Rigidity & + & + & + & - & + \\
\hline Bradykinesia/akinesia & + & + & + & + & + \\
\hline Tremor & + & - & - & - & + \\
\hline Vertical gaze palsy & - & - & + & - & - \\
\hline Increased DTR & + & + & + & - & + \\
\hline Dysautonomia & - & - & - & - & - \\
\hline \multicolumn{6}{|l|}{ Brain MRI findings } \\
\hline Cerebellar atrophy & + & + & + & + & + \\
\hline MCP atrophy & - & - & - & - & - \\
\hline Putamen atrophy & - & - & - & - & - \\
\hline Hot cross bun sign & - & - & - & - & - \\
\hline \multicolumn{6}{|l|}{ Neuromelanin MRI } \\
\hline SN melanin signal & $\downarrow$ & $\downarrow$ & $\downarrow$ & $\downarrow$ & $\mathrm{NE}$ \\
\hline LC melanin signal & $\downarrow$ & $\downarrow$ & $\downarrow$ & $\rightarrow$ & $\mathrm{NE}$ \\
\hline \multicolumn{6}{|l|}{ RI findings } \\
\hline $\begin{array}{l}\text { DAT scintigraphy } \\
\text { SBR (Right/Left) }\end{array}$ & $0.44 / 0.04$ & $3.20 / 3.39$ & NE & $3.08 / 2.71$ & $\mathrm{NE}$ \\
\hline
\end{tabular}

\section{Abbreviations}

DAT, ${ }^{123}$ I-ioflupane dopamine transporter; DTR, deep tendon reflex; LC, locus coeruleus; MCP, middle cerebellar peduncle; NE, not examined; NSDD, nigrostriatal dopaminergic dysfunction; SCA31, 
spinocerebellar ataxia type 31; SBR, specific binding ratio; SN, substantia nigra.

Table 2. Demographic features and results of cross-sectional imaging analysis using MRI planimetry 


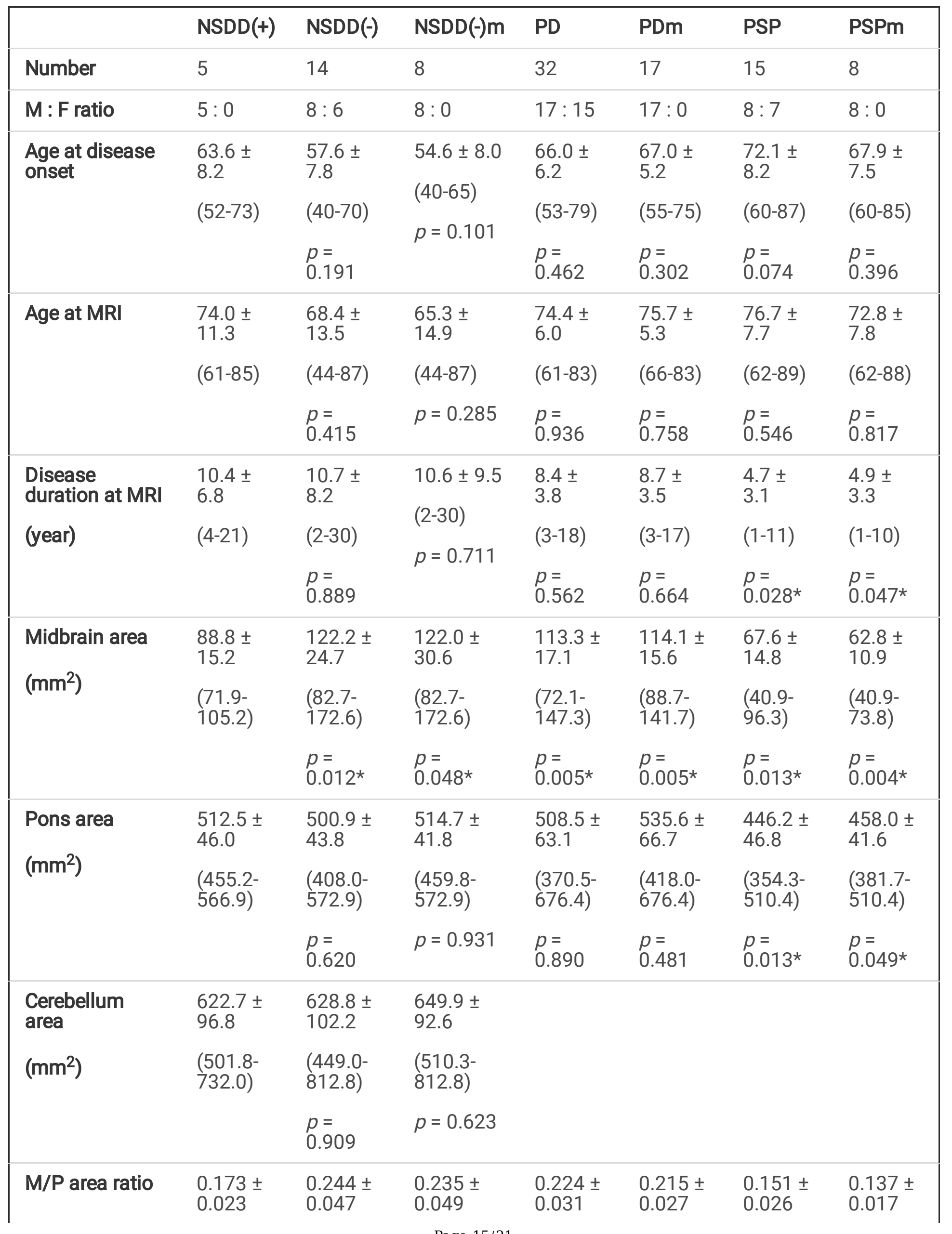




\begin{tabular}{|c|c|c|c|c|c|c|c|}
\hline & \multirow[t]{2}{*}{$\begin{array}{l}(0.148- \\
0.202)\end{array}$} & $\begin{array}{l}(0.180- \\
0.333)\end{array}$ & $\begin{array}{l}(0.180- \\
0.333)\end{array}$ & $\begin{array}{l}(0.146- \\
0.296)\end{array}$ & $\begin{array}{l}(0.146- \\
0.251)\end{array}$ & $\begin{array}{l}(0.107- \\
0.210)\end{array}$ & $\begin{array}{l}(0.107- \\
0.157)\end{array}$ \\
\hline & & $\begin{array}{l}p= \\
0.005^{\star}\end{array}$ & $\begin{array}{l}p= \\
0.022^{*}\end{array}$ & $\begin{array}{l}p= \\
0.001^{*}\end{array}$ & $\begin{array}{l}p= \\
0.006^{\star}\end{array}$ & $\begin{array}{l}p= \\
0.111\end{array}$ & $\begin{array}{l}p= \\
0.007 *\end{array}$ \\
\hline \multirow[t]{3}{*}{$\mathrm{C} / \mathrm{P}$ area ratio } & $\begin{array}{l}1.214 \pm \\
0.142\end{array}$ & $\begin{array}{l}1.255 \pm \\
0.176\end{array}$ & $\begin{array}{l}1.278 \pm \\
0.174\end{array}$ & & & & \\
\hline & $\begin{array}{l}(1.034- \\
1.395)\end{array}$ & $\begin{array}{l}(0.927- \\
1.591)\end{array}$ & $\begin{array}{l}(1.119- \\
1.613)\end{array}$ & & & & \\
\hline & & $\begin{array}{l}p= \\
0.639\end{array}$ & $p=0.502$ & & & & \\
\hline
\end{tabular}

Data are expressed as the mean \pm SD (range).

* Significant difference between NSDD(+) and $\mathrm{X}, \mathrm{X}=\mathrm{NSDD}(-), \mathrm{NSDD}(-) \mathrm{m}, \mathrm{PD}, \mathrm{PDm}, \mathrm{PSP}, \mathrm{PSPm}$.

\section{Abbreviations}

C/P, cerebellum-to-pons; M/P, midbrain-to-pons; NSDD, nigrostriatal dopaminergic dysfunction; NSDD(+), SCA31 with NSDD; NSDD(-), SCA31 without NSDD; NSDD(-)m, male patients with SCA31 without NSDD; PD, Parkinson's disease; PDm, male patients with PD; PSP, progressive supranuclear palsy; PSPm, male patients with PSP; SCA31, spinocerebellar ataxia type 31.

Table 3. Demographic features and results of longitudinal imaging analysis using MRI planimetry 


\begin{tabular}{|c|c|c|c|}
\hline & NSDD(+) & NSDD(-) & NSDD $(-) \mathrm{m}$ \\
\hline Number & 5 & 9 & 6 \\
\hline$M$ : F ratio & $5: 0$ & $6: 3$ & $6: 0$ \\
\hline \multirow[t]{2}{*}{ MRI number } & \multirow[t]{2}{*}{$3.0 \pm 0.7(2-4)$} & $2.8 \pm 1.0(2-5)$ & $3.2 \pm 1.0(2-5)$ \\
\hline & & $p=0.422$ & $p=0.916$ \\
\hline \multirow[t]{2}{*}{ Age at MRI } & \multirow[t]{2}{*}{$69.2 \pm 9.5(56-86)$} & $69.1 \pm 10.3(53-87)$ & $69.3 \pm 10.4(53-87)$ \\
\hline & & $p=0.970$ & $p=0.976$ \\
\hline \multirow{2}{*}{$\begin{array}{l}\text { Disease duration at MRI } \\
\text { (year) }\end{array}$} & \multirow[t]{2}{*}{$6.5 \pm 5.4(1-21)$} & $10.0 \pm 8.5(1-30)$ & $11.4 \pm 9.1(1-30)$ \\
\hline & & $p=0.175$ & $p=0.087$ \\
\hline \multirow[t]{2}{*}{ MRI interval period (year) } & \multirow[t]{2}{*}{$3.2 \pm 3.7(0.0-10.8)$} & $3.1 \pm 4.0(0.0-13.0)$ & $3.6 \pm 4.3(0.0-13.0)$ \\
\hline & & $p=0.842$ & $p=0.819$ \\
\hline \multirow{2}{*}{$\begin{array}{l}\text { Midbrain area } \\
\left(\mathrm{mm}^{2}\right)\end{array}$} & \multirow[t]{2}{*}{$\begin{array}{l}98.1 \pm 14.5(71.9- \\
120.2)\end{array}$} & $\begin{array}{l}114.1 \pm 20.7(82.7- \\
149.8)\end{array}$ & $\begin{array}{l}110.5 \pm 20.3(82.7- \\
149.5)\end{array}$ \\
\hline & & $p=0.012^{\star}$ & $p=0.047^{*}$ \\
\hline \multirow{3}{*}{$\begin{array}{l}\text { Pons area } \\
\left(\mathrm{mm}^{2}\right)\end{array}$} & \multirow{3}{*}{$\begin{array}{l}526.0 \pm 42.3 \\
(455.2-604.9)\end{array}$} & $506.7 \pm 34.0$ & $507.6 \pm 38.6$ \\
\hline & & (454.0-575.5), & $(454.0-575.5)$ \\
\hline & & $p=0.121$ & $p=0.197$ \\
\hline \multirow[t]{3}{*}{$\mathrm{M} / \mathrm{P}$ area ratio } & $0.187 \pm 0.026$ & $0.224 \pm 0.034$ & $0.216 \pm 0.026$ \\
\hline & \multirow[t]{2}{*}{$(0.148-0.238)$} & $(0.176-0.306)$ & $(0.176-0.260)$ \\
\hline & & $p=0.001^{\star}$ & $p=0.003^{\star}$ \\
\hline \multirow{3}{*}{$\begin{array}{l}\text { Reduction ratio of midbrain } \\
\text { area }\end{array}$} & $0.898 \pm 0.074$ & $0.967 \pm 0.046$ & $0.968 \pm 0.043$ \\
\hline & \multirow{2}{*}{$\begin{array}{l}(0.773-0.995), n= \\
10\end{array}$} & $(0.886-1.040), n=16$ & $(0.893-1.040), n=13$ \\
\hline & & $p=0.007^{\star}$ & $p=0.009 *$ \\
\hline \multirow[t]{3}{*}{ Reduction ratio of pons area } & $0.975 \pm 0.062$ & $0.979 \pm 0.026$ & $0.976 \pm 0.024$ \\
\hline & \multirow{2}{*}{$\begin{array}{l}(0.847-1.086), n= \\
10\end{array}$} & $(0.943-1.033), \mathrm{n}=16$ & $(0.943-1.017), n=13$ \\
\hline & & $p=0.859$ & $p=0.985$ \\
\hline \multirow{3}{*}{$\begin{array}{l}\text { Reduction ratio of } \mathrm{M} / \mathrm{P} \text { area } \\
\text { ratio }\end{array}$} & $0.922 \pm 0.078$ & $0.988 \pm 0.049$ & $0.993 \pm 0.051$ \\
\hline & \multirow{2}{*}{$\begin{array}{l}(0.820-1.085), n= \\
10\end{array}$} & $(0.920-1.080), n=16$ & $(0.928-1.080), n=13$ \\
\hline & & $p=0.014^{\star}$ & $p=0.016^{*}$ \\
\hline
\end{tabular}

Data are expressed as the mean \pm SD (range). 
* Significant difference between NSDD(+) and NSDD(-) and between NSDD (+) and NSDD(-)m.

A total of $40 \mathrm{MRI}$ scans ( 15 for $\operatorname{NSDD}(+), 25$ for $\operatorname{NSDD}(-)$, and 19 for $\operatorname{NSDD}(-) \mathrm{m}$ were used to measure the midbrain and pons area to calculate the M/P area ratio.

Abbreviations: M/P, midbrain-to-pons; NSDD, nigrostriatal dopaminergic dysfunction; NSDD(+), SCA31 with NSDD; NSDD(-), SCA31 without NSDD; NSDD(-)m, male patients with SCA31 without NSDD; SCA31, spinocerebellar ataxia type 31.

Figures 

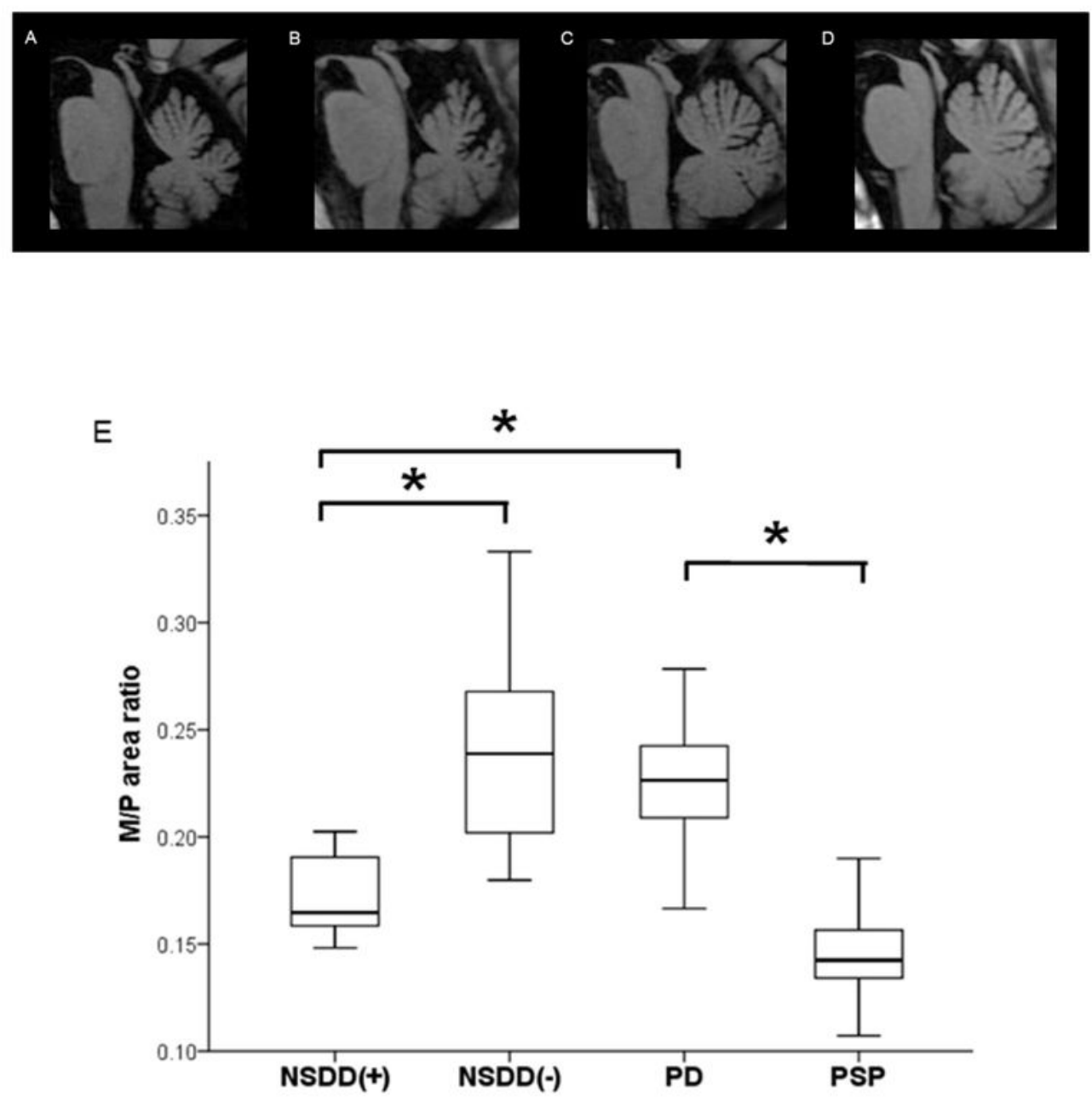

\section{Figure 1}

Midbrain atrophy in a representative case of NSDD and the results of M/P area ratio Midsagittal T1weighted MRI of a representative case from the $\operatorname{NSDD}(+)(A), \operatorname{NSDD}(-)(B), P D(C)$, and PSP (D). (E) Crosssectional imaging analysis of the M/P area ratio showing a clear difference between the $\operatorname{NSDD}(+)$ and $\operatorname{NSDD}(-)$ groups $(p=0.005)$, and between the $\operatorname{NSDD}(+)$ and PD groups $(p=0.001)$. In line with previous studies, the M/P area ratio showed a clear difference between the PD and PSP groups $(p<0.001)$. 
*Significant difference $(\mathrm{p}<0.05)$. M/P, midbrain-to-pons; NSDD, nigrostriatal dopaminergic dysfunction; NSDD(+), SCA31 with NSDD; NSDD(-), SCA31 without NSDD; PD, Parkinson's disease; PSP, progressive supranuclear palsy; SCA31, spinocerebellar ataxia type 31.
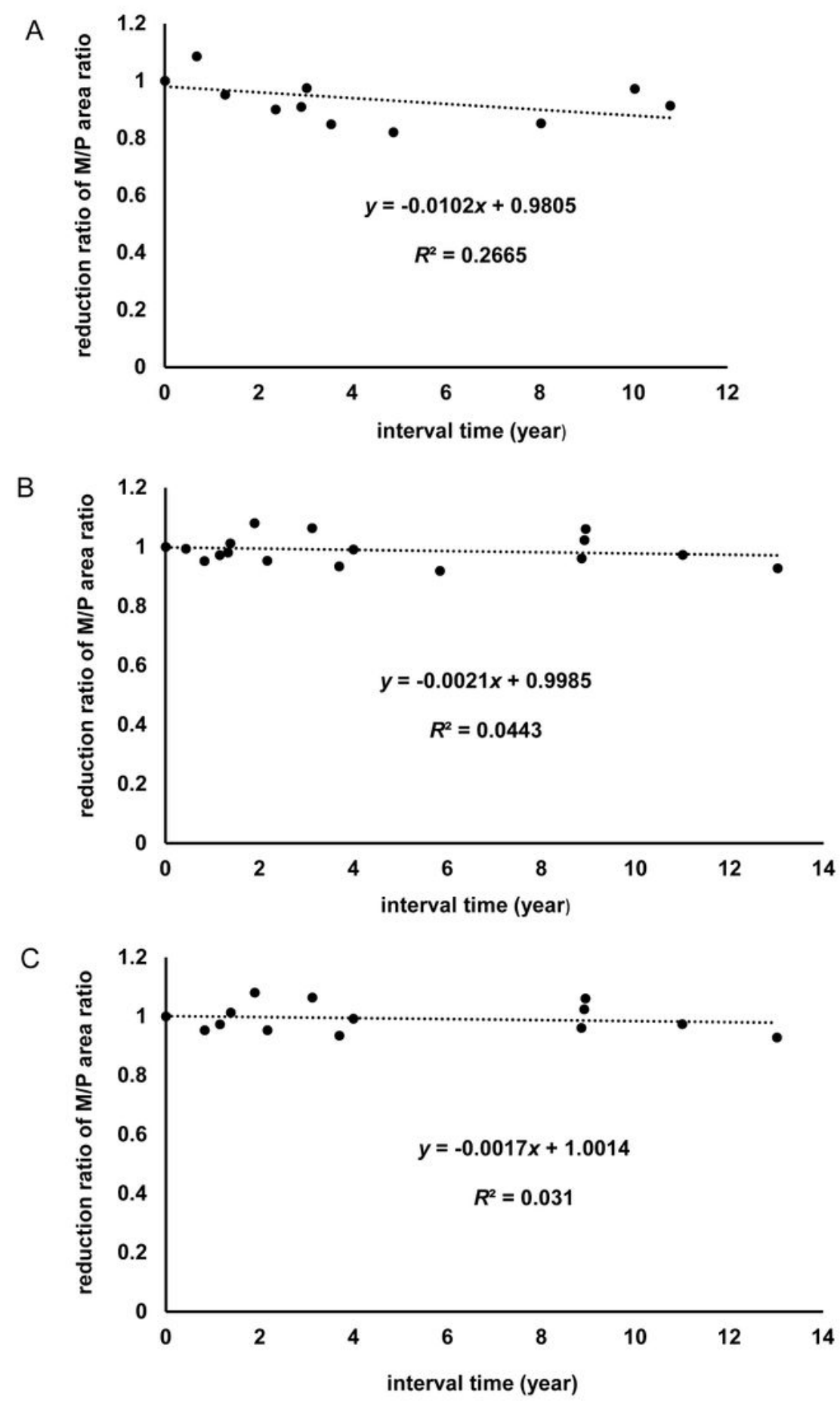

Figure 2

Linear regression analyses of the reduction ratio of the M/P area ratio over time Longitudinal changes in the M/P area ratio were calculated by serial brain MRI obtained from the NSDD $(+)(n=5)(A)$ and NSDD (-) 
$(n=9)(B)$ groups. Male patients in the NSDD (-) group were placed into the male patients with NSDD (-) group $(n=6, \operatorname{NSDD}(-) m)(C) . x$ represents the time interval (year) from the day of the first MRI examination to the second or later MRI examination in each patient. The dependent variable y represents the reduction ratio of the M/P area ratio. The M/P area ratio derived from the first MRI examination was defined as 1 , and the M/P area ratio derived from the second or later MRI was divided by the M/P area ratio derived from the first MRI in each patient. M/P, midbrain-to-pons; NSDD, nigrostriatal dopaminergic dysfunction; NSDD(+), SCA31 with NSDD; NSDD(-), SCA31 without NSDD; NSDD(-)m, male patients with SCA31 without NSDD; SCA31, spinocerebellar ataxia type 31.

\section{Supplementary Files}

This is a list of supplementary files associated with this preprint. Click to download.

- SupplementaryFig.1.pdf

- SupplementaryFile1.docx 